\title{
Determination of the process and parameters of the technology of high-speed railway screw pile technology

\author{
Jun Gao
}

\author{
(Tsinghua university civil engineering department, Beijing haidian 100083) \\ E-mail:policegaojun@163.com
}

Tel number:13476137988

Keywords: High-speed rail; Screw pile; Manufacturability; The test;

Abstract: The high iron screw pile construction technique is a new technique, a kind of foundation reinforcement by representative districts to the manufacturability of pile test, the parameters determined by test pile construction, fixed in time according to the problems found during the process of test pile construction technology, determine the concrete proportions and physical properties of all kinds of materials; The bearing capacity of the single pile is in accordance with the foundation bearing capacity. The construction process and parameters are the basis for evaluation of the quality inspection of the project; To test the selected construction equipment and construction technology; Through the strength of pile body completeness, detection, to determine whether no lateral compressive strength can meet the design strength, to optimize the construction parameters and cement mortar, water cement ratio. Provide reference for the construction and experiment of screw piling for high-speed railway.

\section{Project summary}

Zhengzhou-wanzhou railway has a total length of $286.155 \mathrm{Km}$ in hubei. The D1K386 + $959.108-\mathrm{d} 1 \mathrm{k} 388+261.10$ section of the roadbed is $1301.992 \mathrm{~m}$, and the roadbed has a small distance of 29 \# taitung bridge and a large distance of the no. 2 \# bridge of dongjin 2 \# bridge. Entire section foundation treatment adopts screw pile, pile diameter was $\Phi 0.5 \mathrm{~m}$, pile spacing of $2.3 \mathrm{~m}$ (adjacent down hair line), part of the station line is $2.4 \mathrm{~m}$, pile length is $12-19 \mathrm{~m}$.

\section{Engineering geology and hydrogeology}

\section{engineering geology}

Ridge hillock landform, slightly undulating terrain, natural grade $1^{\circ} \sim 3^{\circ}$, the ground elevation of $70.30 \sim 73.82 \mathrm{~m}$, the relative height difference of $0.09 \sim 3.02 \mathrm{~m}$, the segment of vegetation growth, many bi farmland, cottages, roads, ponds, wasteland, etc., the traffic is more convenient. There are seven ponds in the area and the amount of water in the dry season is small. (0) Q4al + pl surface is silt, black gray. (0-1) Q4al + pl is silt clay, black gray, thickness $1.7 \sim 3.1 \mathrm{~m} .(1-3) \mathrm{Q} 2 \sim 3 \mathrm{al}+\mathrm{pl}$ powder clay, brown yellow, malleable, thickness $0.7 \sim 10.5 \mathrm{~m}$. (1-4) Q2 3al + pl powder clay, brown yellow, malleable, 0.6-22.4 m. (4-3) Q2 3al + pl fine sand, medium, brown yellow, thickness $1.6 \sim 14.6 \mathrm{~m}$. (6-2) Q2 $\sim 3$ al + pl coarse sand, medium, brown yellow, thickness $1.6 \sim$ $16.1 \mathrm{~m}$. (7-2) Q2 3al + pl fine gravel soil, medium and brown yellow, thickness $1.7 \sim 16.6 \mathrm{~m}$. (10-1) Q2 3al + pl calcium tuberculosis, gray, hard, thickness $4.2 \sim 17.7 \mathrm{~m}$. (1-1) N mud limestone, light yellow, gray white, all wind hua, thick $7 \sim 8 \mathrm{~m}$. (1-2) N mud limestone, light yellow, gray white, strong wind, heavy $5.2 \sim 12.8 \mathrm{~m}$. (1-3) N mud limestone, light yellow, gray white, weak wind, thick $5.1 \sim 13 \mathrm{~m}$. (2-1) k-e clay sandstone, light reddish brown, full blown, thick $4.3 \mathrm{~m}$. (2-2) 
k-e clay sandstone, light reddish brown, strong wind, thick, $1.8 \sim 9.39 \mathrm{~m}$. (2-3) k-e clay sandstone, light reddish brown, weak wind, thick $3.6 \sim 18.01 \mathrm{~m}$.

\section{Hydrogeology}

The surface water is mainly of aqueduct, and receives the surface runoff and the rainfall of the atmosphere. No chemical erosion of surface water, no chlorine-salt environmental damage, no salt crystallization damage. No chemical erosion, no chlorine-salt environmental damage, no salt crystallization. The scale of the carbonization environment is T2.

\section{The purpose of the experiment and the test pile parameters}

\section{Objective}

Choose a representative area for the manufacturability of pile test, all the parameters determined by test pile construction, fixed in time according to the problems found during the process of test pile construction process, specific as follows:

1.Determining the physical properties of concrete and various raw materials;

2.Determining the bearing capacity of a single pile, which conforms to the foundation bearing capacity;

3.To determine the basis for evaluation of the quality of the construction of this project;

4.Testing the selected construction equipment and construction techniques;

5.Pile body integrity, strength testing, to determine whether no lateral compressive strength can meet the design strength, to optimize the construction parameters and cement mortar, water cement ratio.

\section{Test the relevant parameters of the pile}

Pile spacing for $\Phi 0.5 \mathrm{~m}$, pile diameter of $2.3 \mathrm{~m}$ (adjacent down hair line), part of the station line is $2.4 \mathrm{~m}$, pile length is $12-19 \mathrm{~m}$.

\section{The construction of test pile}

\section{The principle of screw pile technology}

The screw pile is a kind of cross-sectional injection pile, which is not collected in the construction process, and has obvious squeezing effect on the soil. Through the compacting of the natural foundation, the compressibility of the soil is decreased, the bearing capacity of the natural foundation is improved, and the settlement of the foundation is decreased.

The pile is made up of the upper and lower parts, and the upper part of the pile is the cylinder, which is the same as the normal filling pile, and the bottom is a threaded pile. The length of the upper and lower part is regulated according to the soil quality of the foundation, and there is no fixed proportion. Because of the foundation soil has the characteristics of soft down hard on commonly, therefore, usually in the soil bearing capacity is less than $120 \mathrm{kpa}$ cylinder pile, the bearing capacity of more than $120 \mathrm{kpa}$ made screw pile in the soil, this setting can give full play to the bearing capacity of foundation. Figure 1 screw structure diagram. 

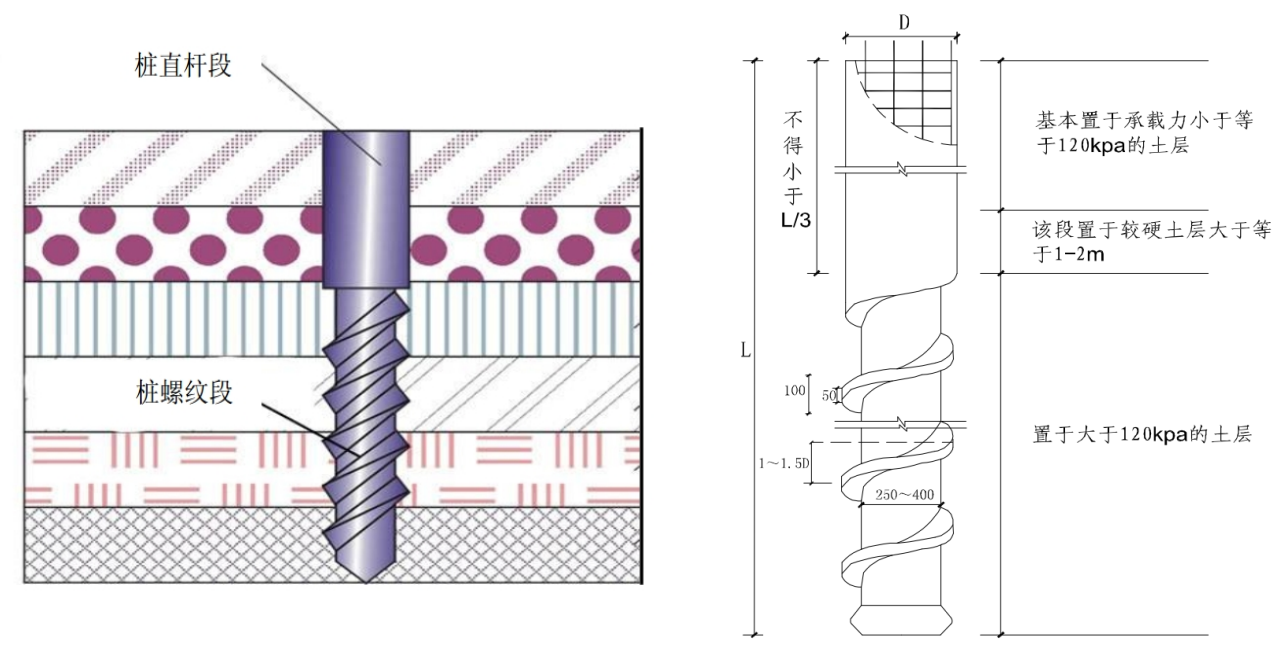

Figure 1 Screw structure diagram.

\section{The construction process}

\section{The site is cleared and compacted}

Prior to construction machinery in the construction area of land clearing, leveling, and make the necessary compaction, to ensure that the machinery can present smoothly in place, move, do not produce deflection.

\section{The measuring set}

The construction area, and the pile number, before the release of the construction of the pile location accurate location, pile is a center with steel insert ground not less than $20 \mathrm{~cm}$, with white express. Put control of pile, pile lofting using measurement class coupled with big steel rule setting, ensure that pile lateral deviation is not more than \pm 5 , the construction control of the elevation of pile in the bottom of the pile cap is higher than the design elevation $50 \mathrm{~cm}$, prevent waste mixture of super.

\section{The rig is in position}

After the rig is in place, the drill pipe should be pointed at the center of the pile, ensuring that the vertical tolerance of screw pile is not greater than $1 \%$. The vertical degree of the hole is measured by the method of hanging ball on the drill rack, and the vertical degree of the drill pipe can be controlled by the rig's own vertical adjustment device. Before the construction of each pile, the technical personnel of the site are inspected for the position of the pile and the vertical degree, and the drill can be opened after meeting the requirement.

\section{Drilling into holes}

When the drill starts, turn off the drill valve and move the drill pipe down to the ground. Generally, it should be slower and faster, so that the drill pipe is not shaken and the hole is checked so that it can be corrected in time. In the process of pore forming, shaking, or difficult to drill, if discover drill pipe should be slow drilling speed, otherwise easy to cause the borehole deflection, displacement, and even make the damage of drill pipe, drill. In the process of drilling, the pile machine control system strictly controls the drop speed and rotation speed of the drill pipe to make the two match. When forming a column, the drill pipe is required to be reduced by one pitch, and the drill pipe is rotated more than two weeks. When the thread is formed, it is required that the screw drill rod should be reduced by one pitch, and the drill pipe will be rotated for a week, drilling into the design depth of the screw thread. The drill should be stopped immediately when there are obstacles, and then redrilling after removing obstacles. 


\section{Reverse rotating the drill pipe and pump the concrete}

Screw pile hole reaches the design elevation, stop drilling, start pumping concrete, after the drill core tube filled with concrete, counter-rotating ascending pipe, screw pile machine lift control system should be strictly controlled in the process of drilling pipe winding speed and rotational speed, the soil along has formed the trajectory drill pipe thread reverse rotation, drill pipe rotating revolutions and keep the speed synchronization and matching to uniform tube speed control, for drill pipe rotation, a pitch pipe up. At the same time, the pump delivers high pressure fine stone concrete to fill the thread space that is generated by the rotation of the drill pipe. When the design of drill pipe up to the threaded section end face height, drill pipe again positive rotation or directly increase with cylindrical space, at the same time bit pumping concrete pouring high-pressure pipe produced by direct ascension with cylindrical space, until the cap design elevation.

\section{Displacement, construction of the next pile}

After the completion of the construction, the pile is protected and the next pile construction is repeated.

\section{Test pile conclusion}

\section{Equipment selection and main machinery}

The drill rig use theLDd- $1 \mathrm{dc}$ power pile, $60 \mathrm{~B}$ concrete pump, and the pipe speed $2 \mathrm{~m} / \mathrm{min}$ according to the field geology situation. Other equipment: one machine for pile head ring cutter, one concrete pump car (60B), one loader of 50B (dou rong $3.0 \mathrm{~m}^{3}$ ), one concrete tanker, one excavator.

\section{Identify the match ratio}

The pile material is made of gravel, stone dust or sand, fly ash, cement and water. Cement pile body adopts the P.O 42.5 ordinary Portland cement (local water erosion sex, according to the grades of the role of chemical erosion environment with a certain weight ratio of cement), cement mortar is not more than $200 \mathrm{~kg} / \mathrm{m}^{3}$, adding high quality fly ash (level is not lower than III), dosage of fly ash is $70 \sim 90 \mathrm{~kg} / \mathrm{m}^{3}$, rate of stone chips generally at about 0.3 , gravel aggregate, meet the requirements of grading, loose bulk density is greater than $1500 \mathrm{~kg} / \mathrm{m}^{3}$. The maximum size of the gravel: the vibration sink method is not more than $40 \mathrm{~mm}$, the long spiral borehole and the pump pressure mixing method is not greater than $25 \mathrm{~mm}$. Cement: fine aggregate: coarse aggregate: powder coal ash: mixing water $=1: 4.55: 53: 0.58: 0.033: 0.70$.

\section{The technical points of the determination}

(1) Before construction, the testing room shall be carried out in accordance with the design requirement, and the mixing materials shall be made in accordance with the mixing ratio. The collapse degree of a long spiral drilling and in-line pump pressure mixing is $180 \sim 200 \mathrm{~mm}$.

(2) In place of the pile machine, the adjustment of the drill pipe is perpendicular to the ground to ensure that the vertical deviation is not greater than $1 \%$. The pile bit deviation should not be greater than $50 \mathrm{~mm}$ for the pile foundation.

(3) Control the depth of the drilled hole and ensure that the pile length deviation is within the range of $+100 \mathrm{~mm}$.

(4)When the drill pipe rotation pumping mixture of revolution and keep the speed synchronization and matching to the uniform control tube speed, for drill pipe rotation, a pitch pipe up. At the same time, the pump delivers high pressure fine stone concrete to fill the thread space that is generated by the rotation of the drill pipe. When the design of drill pipe up to the threaded section end face height, drill pipe again positive rotation or directly increase with cylindrical space, at the same time bit 
pumping concrete pouring high-pressure pipe produced by direct ascension with cylindrical space, until the cap design elevation.

(5)Construction, pile top elevation should be higher than the design elevation, according to the form of pile spacing, pile length, higher than that of the site geological conditions and determined comprehensively according to order, generally should not be less than $0.5 \mathrm{~m}$.

\section{Test}

\section{Test content}

Pile body integrity, single pile vertical bearing capacity. Pile body completeness in 28 days after the construction completion the nondestructive testing method for pile quality testing, NDT testing pile number not less than $10 \%$ of the total number of piles, and each worksite is not less than three root; Vertical bearing capacity of single pile inspection should be completed in the construction of 28 days using the load test method of detection, detection for not less than $0.2 \%$ of the total number of piles, and each worksite of not less than three root.

(1) The test cube strength of the age of 28 days is greater than $20 \mathrm{MPa}$.

(2) The integrity of the pile was detected by the low strain reflection wave method after 28 days.

\section{Test results}

(1) The classification and discrimination criteria of the body integrity of the low strain reflection method:

Class I pile: the pile is complete. $2 \mathrm{~L} / \mathrm{c}$ no defect emission wave prior to time, with a base emission wave (L - long, $\mathrm{m}$; c-longitudinal wave velocity, $\mathrm{m} / \mathrm{s}$ ).

Class II pile: whole. The $2 \mathrm{~L} / \mathrm{c}$ moment has a slight defect emission wave and a base emission wave.

Class III pile: there are obvious defects in the pile and the bearing capacity of the pile is affected. $2 \mathrm{~L} / \mathrm{c}$ is preceded by a significant defect emission wave, no pile-bottom emitting wave.

Class IV pile: a serious defect in the pile, which affects the bearing capacity of the pile. $2 \mathrm{~L} / \mathrm{c}$ at a time when serious defect emission wave or periodic reflection, no pile bottom launch wave; because of the severe defect of the pile, the waveform is vibrating with low frequency and vibration amplitude, and no base emission wave.

(2) The integrity of the pile: the test pile is 4 , the I pile is 100 percent, the result: qualified.

(3) The strength of the pile: 3 groups of test blocks, 28 days maintenance, the test of the strength of the test block, the actual compressive strength is $23.1 \mathrm{MPa}$. Achieve the design strength.

\section{Conclusions and Suggestions}

Prior to construction, the testing room should be carried out according to the design requirement, and the mixing material shall be made according to the mixing ratio.

In the case of the two parts of the pile, it is not allowed to cause any of the lower part of the pile to fracture and disturb the soil.

Control the depth of the drilled hole to ensure that the pile length deviation is within the range of $+100 \mathrm{~mm}$.

When pumping mixture pipe rotating revolutions and keep the speed synchronization and matching to the uniform control tube speed, for drill pipe rotation, a pitch pipe up. 


\section{Reference}

[1] new railway zhengzhou to wanzhou xiangyang dongjin station design drawing, "railway roadbed foundation processing" (2014) 2028, roadbed engineering design atlas drawings.

[2] "the technical regulations for the construction of high-speed railway subways" (Q/CR9602-2015).

[3], "quality acceptance criteria for high speed rail engineering construction" (TB10751-2010) [S].

[4] "technical regulations for the treatment of railway engineering" [S]. 2015.

[5], "the technical regulations for the testing of railway engineering piles" (TB1023-2008). 